
https://doi.org/10.30534/ijeter/2019/087112019

\title{
A Methodology for Big Data Analytics and IoT-Oriented Transportation System for future implementation
}

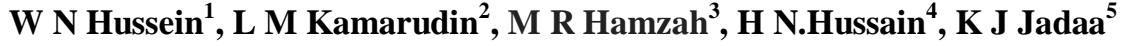 \\ ${ }^{1}$ School of Human Development and Technocommunication, Universiti Malaysia Perlis, \\ Malaysia,Waleedn9@yahoo.com \\ ${ }^{2}$ Centre of Excellence for Advanced Sensor Technology (CEASTech), School of Computer and Communication \\ Engineering, Universiti Malaysia Perlis, Malaysia, latifahmunirah@ unimap.edu.my \\ ${ }^{3}$ School of Human Development and Technocommunication, Universiti Malaysia Perlis, \\ Malaysia,rezal@unimap.edu.my \\ ${ }^{4}$ Faculty of Science, University of Basrah Iraq, alhashimy@gmail.com \\ ${ }^{5}$ School of Computer and Communication Engineering, Universiti Malaysia Perlis, Malaysia, \\ khalid.jamal.jadaa@gmail.com
}

\begin{abstract}
This paper presents a review of past related studies on big data analytics and IoT oriented transportation system. This paper discussed the intelligent transportation system, benefits, and issues related to the system. Also, this paper presents the use of big data analytics and IoT in transportation system. The benefits and issues related to big data analytics and IoToriented transportation system were discussed. The methodology that will be used to obtain data on the impact of big data analytics and IoT in the transportation system was also presented. This paper aims to understand the impact of big data analytics and IoT in transportation system for future implementation. The outcome of this research will be a unified implementation framework for big data analytics and IoT-oriented transportation system to achieve customer satisfaction.
\end{abstract}

Key words: big data analytics, intelligent transportation system, internet of things, IoT.

\section{INTRODUCTION}

The Internet of Things (IoT) and big data analytics are the major backbones in developing an intelligent transportation system. IoT is a way to make objects interact and communicate with each other or between objects and people this will result in huge information received from different devices that use the internet to communicate. The communication between these object help in identifying various data that can be used to analyze the information needed by different sectors to make good use of the obtained data [1-4]. IoT is additionally supported by the tangible and correspondence capacities of the associated physical electronic items. Through these items, the area is observed and revealed, and imparting electronic devices are modified to act as indicated by the data it got $[5,6]$.
Basically, IoT consists of adding sensing and communication capabilities to varieties of physical objects, then, connecting them together over the internet for different purposes. These purposes range from monitoring their environment, status report, and receiving instructions, to taking action based on the information they receive. Therefore, theoretically, any object can be used as a source of information about another object $[5,6]$.

Big data, on the other hand, is the data received from different objects which are huge compared with ordinary data that is used by normal computers [7], but is usually generated due to the intercommunication among the physical electronic objects [5]. Big data analytics divulges novel information and insights on the workability of these physical objects and interactions, thus allows improvement in terms of their functioning. Furthermore, communication between machine to machine devices and cross-platform data analytics enables interaction between these devices, much like humans' interaction over the internet $[8,9]$.

This research aims to understand the impact of big data analytics and IoT in intelligent transportation system, and to understand the benefits and issues of using big data analytics and IoT in transportation system, which will help transportation sector to take notes before going for actual future implementation.

\section{INTELLIGENT TRANSPORTATION SYSTEM}

Intelligent transportation systems are a composite of information technologies strategically combined and deployed, with the use of data-driven insights, to make the transportation process more efficient and result-oriented [10]. It is a consortium of technologies and electronic applications that is wide and growing in usage. Many industries and sectors, such as healthcare, manufacturing, security, amongst others, are already being revolutionized by information technology (IT) [11]. The transportation sector is also 
presently experiencing technology-driven transformation. Countries like Portugal, Singapore, Germany, and Britain are taking the lead in the transformation of transportation systems to heavily technology-enabled infrastructure which is evolving into an intelligent transportation system $[12,13]$. An intelligent transportation system is now a major tool for solving age-long challenges of surface transportation. Intelligent transportation system is built on an "infostructure", i.e. information-driven infrastructure to support the physical transportation infrastructure (Sia Partner, 2016).

\section{BENEFITS OF INTELLIGENT TRANSPORTATION SYSTEM}

The intelligent transportation system helps in enhancing mobility, increasing safety, improving operational performance, congestion in particular, and contributes to vehicle safety reassessment which has always been passengers' protection in the event of a crash [14]. Job opportunities also can be derived from people. It also creates job opportunities for citizens. The V2I and V2V, for example, Japan's Smartway of the United States' IntelliDrive, are being intended for helping drivers in maintaining a strategic distance from the mishap out and out. For example, IntelliDrive arrangement of the U.S. could conceivably address 82 percent of vehicle crash cases which include healthy drivers [15]. An intelligent transportation system also maximizes the infrastructure capacity and reduces the need for building the additional capacity of highway [16]. For instance, at the point when data of real-time traffic is added to U.S. traffic signal lights, it significantly improved the flow of traffic and reduced stops by 40 percent, reduce time of travel by 25 percent, cut consumption of gas by 10 percent ( the annually of gas is about 1.1 million gallons), while the emission is cut by and by 22 percent [17]. D espite the massive and significant benefits in deploying intelligent transportation system, it is still being under-invested in many countries, and this is due to associated challenges that are involved in the development and deployment of the systems.

\section{CHALLENGES OF INTELLIGENT TRANSPORTATION SYSTEM}

The need to deploy intelligent transportation systems at a national level with all individuals and stakeholders readily participatory in order to achieve the desired extensive benefits is one of the major challenges of countries willing to adopt intelligent transportation systems $[18,19]$. There is a need for transportation system to operate at some network scale which is in the case of the transportation system is national level, especially for technologies like traffic signals and ramp meters to deliver the required benefits for customers. [20-22]. The adoption must be overall, and this also, in turn, raises the issues of interdependency of system, the affection of network. For instance, for VII to be effective, just like the U.S.'s IntelliDrive, it must work on a national basis $[14,16]$.

\section{IoT AND BIG DATA ANALYTICS-BASED TRANSPORTATION INFORMATION SYSTEMS}

IoT and big data analytics have been used as infrastructural technology in designing and developing certain information systems for the transportation sector. These IoT and big data analytics-based transportation information system are intelligent transportation systems. In the following sub-sections, Advanced Traveler Information Systems, Advanced Transportation Management Systems, Intelligent Transportation Pricing System, and Advanced Public Transportation System will be discussed.

\subsection{Advanced Traveler Information Systems}

Advanced Traveler Information System provides drivers with real-time travel and traffic information, including routes and schedules of transit, and directions of navigation. It also gives information regarding congestion, weather conditions, accidents or ongoing road repair work.

\subsection{Advanced Transportation Management Systems}

Advanced Transportation Management Systems (ATMS) is also an intelligent transportation application which focuses on the traffic control devices, such as ramp metering, traffic signals, and the dynamic (or "variable") message signs located on highways.

\subsection{Intelligent Transportation Pricing Systems}

Pricing and toll fee collection is another functionality of the intelligent transportation system handled by intelligent transportation pricing systems. Electronic toll collection (ETC) is the most common application in this regard (Ezell, 2010). It is now better technologically-supported, hence allows "road user charging," where tolls can be paid automatically by drivers.

\subsection{Advanced Public Transportation Systems}

Advanced Public Transportation Systems (APTS) are generally public transportation management technologies. A typical example of APTS is automatic vehicle location (AVL) which enables transit vehicles to report their current location. It, therefore, aids the construction of real-time view of all public transportation system assets for the traffic operations manager.

\section{IMPLEMENTING INTERNET OF THINGS (IOT) AND BIG DATA ANALYTICS IN TRANSPORTATION SYSTEM}

The benefits and challenges of implementing IoT and big data analytics in the transportation sector are shown in the following sub-sections. For our research known the benefits and issues of big data analytics and IoT in the transportation system can help in providing a clear understanding of the factors that influence the implementation success. 


\subsection{Benefits of big data analytics and IoT oriented transportation system}

Previous studies have reported the benefits related to big data analytics and IoT oriented transportation system. The benefits of big data analytics and IoT based transportation system are summarized in Table 1.

Table 1: The benefits of big data analytics and IoT oriented transportation system

\begin{tabular}{|c|c|c|}
\hline Benefits & Description & Authors \\
\hline $\begin{array}{l}\text { Increasing driver } \\
\text { and pedestrian } \\
\text { safety }\end{array}$ & $\begin{array}{l}\text { IoT and big data } \\
\text { analytics-dependent } \\
\text { information } \\
\text { technologies employed } \\
\text { in the transportation } \\
\text { sector reduce the } \\
\text { accident rates, thus } \\
\text { increase driver and } \\
\text { pedestrian safety. }\end{array}$ & [10] \\
\hline $\begin{array}{l}\text { Improving the } \\
\text { operational } \\
\text { performance of } \\
\text { the transportation } \\
\text { network }\end{array}$ & $\begin{array}{l}\text { Intelligent } \\
\text { transportation system } \\
\text { improves the transpor- } \\
\text { tation network } \\
\text { performance of a } \\
\text { country by maximizing } \\
\text { the existing } \\
\text { infrastructure capacity } \\
\text { and reducing the need } \\
\text { to build additional } \\
\text { highway capacity }\end{array}$ & [23] \\
\hline $\begin{array}{l}\text { Enhancing } \\
\text { mobility and } \\
\text { convenience }\end{array}$ & $\begin{array}{l}\text { By providing real-time } \\
\text { traveler information to } \\
\text { motorists and mass } \\
\text { transit users, IoT and } \\
\text { big data } \\
\text { analytics-based } \\
\text { transportation systems } \\
\text { enhance users' routes } \\
\text { and navigation } \\
\text { capability. }\end{array}$ & [24] \\
\hline $\begin{array}{l}\text { Delivering } \\
\text { environmental } \\
\text { benefits }\end{array}$ & $\begin{array}{l}\text { By reducing } \\
\text { congestion, enabling } \\
\text { smooth traffic flow, } \\
\text { teaching motorists the } \\
\text { efficient way of } \\
\text { driving, and reducing } \\
\text { the need to build } \\
\text { additional roadways. }\end{array}$ & [25] \\
\hline $\begin{array}{l}\text { Boosting } \\
\text { productivity, } \\
\text { economic, and } \\
\text { employment } \\
\text { growth }\end{array}$ & $\begin{array}{l}\text { By ensuring that people } \\
\text { and products arrive at } \\
\text { their designated } \\
\text { destinations in a quick } \\
\text { and efficient manner } \\
\text { that improves the } \\
\text { transportation } \\
\text { performance of the } \\
\text { country. }\end{array}$ & [26] \\
\hline
\end{tabular}

These benefits help the transportation sector to remain competitive, increase productivity and bottom-line, and enhance customer loyalty and satisfaction.

\subsection{Problems of big data analytics and IoT oriented transportation system}

There are some issues related to big data analytics and IoT in intelligent transportation system. One of the major is heterogeneous. There is, therefore, a need to create a smart network of things that interact with each other and integrate many different technologies proprietary. This helps in processing different businesses, different logistical chain actors and even technologies from different parts of the world [27, 28]. Resolving this requires continuous work on a uniform central deployment framework among the IT providers. Issues with interdependency are also critical for big data analytics and IoT in ITS. It was reported that most intelligent transportation systems, especially those primed to deliver the most extensive benefits to the transportation network must be scalable [29]. At the national level, the system must be adopted in view of addressing the set of system interdependency, system coordination challenges and the network effect. The uncertain market has also been discussed in recent publications. The development of ITS entails much higher risk than numerous different items and administrations, mostly on the grounds that legislatures are key purchasers, and in certain nations, like United States, there have been mixed signals as how reliable they are as purchasers (U.S Department of Transportation, 2002). Business process reengineering has also been mentioned in recent publications.

IoT requires the adoption of new technology, rethinking, and reengineering of the entire processes of business linked to it. This poses an obvious challenge because of the time and effort that must be invested in it for optimal benefits [30]. This can be solved by identifying the main needs of the business which should adhere to the IoT system, followed by the detail of the to-be business process, and an operational analysis that identifies the main technological requirements.

These problems and issues of big data analytics and IoT in the transportation system can make the transportation sector hesitate to implement big data analytics and IoT. Therefore there is a need to identify the implementation success factors for big data analytics and IoT based transportation system before moving towards these technologies.

\section{METHODOLOGY}

Figure 1 presents the steps that have been conducted in this research. A qualitative approach was used in this research. The data will be collected using a systematic literature review and in-depth interview within a case study using a semi-structured questions with experts in the field of big data analytics and IoT-oriented transportation system a face to face interview will be conducted with these experts. The analysis of the data gathered from the in-depth interviews will be 
analyzed using Nvivo software to identify the factors and related elements that impact the implementation of big data analytics and IoT based transportation system. For our research this finding as mentioned will help to understand the impact of big data analytics and IoT in the intelligent transportation system, and how IoT and big data analytics have been used as models in designing and developing certain information systems for the transportation sector. The findings of this study also indicate that it is worthwhile for transportation sector to take note of the results of this study before going for the actual implementation of big data analytics and IoT based transportation system. Our outcome will be a unified implementation framework for big data analytics and IoT oriented transportation system.

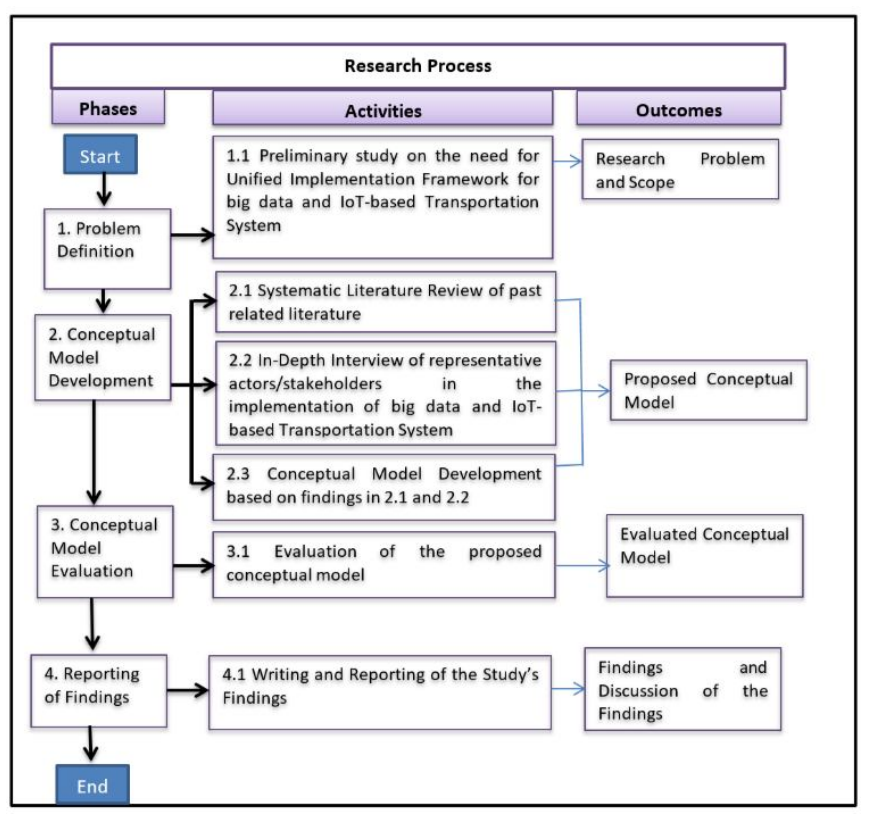

Figure 1: The Research Process for this Study

\section{CONCLUSION}

The intelligent systems provide actionable information that supports decision making in critical instances, such as driver's choice of the route to take, the time to travel, and passengers' decision on whether to use personal cars or take mass transit. In this paper, the impact of big data analytics and IoT in the transportation system was discussed to give clear understanding of these technologies within the transportation sector and to acknowledge the factors that may affect the implementation of intelligent transportation system. The methodology that will be used is also described. This study is about understanding the impact of big data analytics and IoT in transportation system. The finding of our research will be used to propose a unified implementation framework for big data analytics and IoT based transportation system.

\section{REFERENCES}

[1] X. Wang and Z. Li. Traffic and Transportation Smart with Cloud Computing on Big Data. IJCSA, vol. 13, pp. 1-16, 2016.

[2] J. M. F. Calado, L. A. Osório, and R. Prata. An Adaptive IoT Management Infrastructure for EcoTransport Networks.In the book "Risks and Resilience of Collaborative Networks". Working conference on vertual Enterprise.Springer Chapter 4, pp. 285-296,2015.

https://doi.org/10.1007/978-3-319-24141-8_26

[3] W. N. Hussein, L. M. Kamarudin, H. N. Hussain, A. Zakaria, R. Badlishah Ahmed, and N. A. H. Zahri, "The Prospect of Internet of Things and Big Data Analytics in Transportation System," J. Phys. Conf. Ser., vol. 1018, no. 1, 2018.

https://doi.org/10.1088/1742-6596/1018/1/012013

[4] H. Zhou, B. Liu, and D. Wang. Design and research of urban intelligent transportation system based on the internet of things. Internet of Things, ed: Springer, 2012, pp. 572-580.

https://doi.org/10.1007/978-3-642-32427-7_82

[5] R. H. Weber. Internet of Things: New security and privacy challenges.Computer Law \& Security Review, vol. 26, pp. 23-30, 2010. https://doi.org/10.1016/j.clsr.2009.11.008

[6] W. N. Hussein, H. N. Hussain, and L. M. Kamarudin, "Unified implementation framework for big data analytics and internet of things-oriented transportation system," J. Eng. Appl. Sci., vol. 13, no. 11, pp. 4217-4227, 2018. DOI: 10.36478/jeasci.2018.4217.4227

[7] B.Marfo and G. Farooq. A Perspective on the Challenges and Opportunities for Privacy-Aware Big Transportation Data. Journal of Big Data Analytics in Transportation, vol 1,pp.1-23,2019. https://doi.org/10.1007/s42421-019-00001-z

P. Zadrozny and R. Kodali. Big Data Analytics Using Splunk: Deriving Operational Intelligence from Social Media, Machine Data, Existing Data Warehouses, and Other Real-Time Streaming Apress.pp 345, 2013.

https://doi.org/10.1007/978-1-4302-5762-2

[9] C. Zins. Conceptual approaches for defining data, information, and knowledge. Journal of the Association for Information Science and Technology, vol. 58, pp. 479-493, 2007.

https://doi.org/10.1002/asi.20508

[10] S. Ezell. Intelligent transportation systems. The Information Technology \& Innovation Foundation, vol. 34,pp 20-30, 2010.

[11] W. N. Hussein, R. Sulaiman, and A. K. Hamzah, "E-business and cloud computing awareness for Malaysian SMEs: A recommendation from academic and industry perspectives," in 2013 International Conference on Research and Innovation in Information Systems (ICRIIS), 2013, pp. 180-185.

https://doi.org/10.1109/ICRIIS.2013.6716705 
W N Hussein et al., International Journal of Emerging Trends in Engineering Research, 7(11), November 2019, 449 - 453

[12] K. J. Jadaa, L. M. Kamarudin, R. B. Ahmad, and W. N. Hussein, "Multi Objects Detection and Tracking System for Smart Home using Wireless Sensor Network," Int. J. Adv. Trends Comput. Sci. Eng., vol. 8, no. 5, pp. 2434-2441, 2019. https://doi.org/10.30534/ijatcse/2019/86852019

[13] K. J. Jadaa, L. M. Kamarudin, and R. B. Ahmad, "Detection and Tracking Survey for Smart Home Using Wireless Sensor Network," J. Eng. Appl. Sci., vol. 14, no. 9, pp. 3119-3129, 2019.

[26] D. Pojani and D. Stead. Sustainable urban transport in the developing world: beyond megacities. Sustainability, vol. 7, pp. 7784-7805, 2015.

https://doi.org/10.3390/su7067784

[27] W. N. Hussein, L. M. Kamarudin, H. N. Hussain, M. R. Hamzah, and K. J. Jadaa, "Technology Elements that Influence the Implementation Success for Big Data Analytics and IoT- Oriented Transportation System," Int. J. Adv. Trends Comput. Sci. Eng., vol. 8, no. 5, pp. 2347-2352, 2019.

https://doi.org/10.30534/ijatcse/2019/74852019

[28] A. K. Bhadani and D. Jothimani. Big Data: Challenges, Opportunities, and Realities: Effective Big Data Management and Opportunities for Implementation (pp. 1-24). Hershey,IGI,Global.PP.1-24,2016.

https://doi.org/10.4018/978-1-5225-0182-4.ch001

[29] N. A. Khan. Real time predictive monitoring system for urban transport.Faculty of Science, Engineering and Computing, Kingston University London, United Kingdom.PhD Thesis,Kingston University, 2017.

[30] J. Barbaresso, G. Cordahi, D. Garcia, C. Hill, A. Jendzejec, and K. Wright, "USDOT's Intelligent Transportation Systems (ITS) ITS Strategic Plan 2015-2019,pp 16-26, 2014. 